\title{
Hormonal and Psychobehavioral Predictors of Weight Loss in Response to a Short-Term Weight Reduction Program in Obese Women
}

\author{
V. HAINER ${ }^{1}$, K. HLAVATÁ ${ }^{1}$, M. GOJOVÁ ${ }^{2}$, M. KUNEŠOVÁ ${ }^{1}$, M. WAGENKNECHT ${ }^{1}$, \\ V. KOPSKÝ ${ }^{1}$, J. PAŘÍZKOVÁ ${ }^{1}$, M. HILL ${ }^{1}$, J. NEDVÍDKOVÁ ${ }^{1}$ \\ ${ }^{1}$ Institute of Endocrinology, Prague, Czech Republic, ${ }^{2}$ Obesity Management Unit, Lipová - lázně, \\ Czech Republic
}

Received November 12, 2007

Accepted January 17, 2008

On-line February 13, 2008

\begin{abstract}
Summary
Among the factors influencing weight loss and maintenance, psychobehavioral, nutritional, metabolic, hormonal and hereditary predictors play an important role. Psychobehavioral factors influence adherence to lifestyle changes and thus weight loss maintenance. The outcome of short-term weight reduction treatment is mainly affected by changes in energy and nutrient intake and physical activity and thus the impact of hormones can possibly be obscured. In order to reveal hormonal determinants of weight loss, a 4-week in-patient comprehensive weight reduction program was introduced in which food intake and physical activity were under the strict control. Women ( $n=67$, BMI: $32.4 \pm 4.4 \mathrm{~kg}$; age: $48.7 \pm 12.2$ years) who exhibited stable weight on a $7 \mathrm{MJ} /$ day diet during the first week of weight management were given a hypocaloric diet yielding daily energy deficit 2.5 MJ over the subsequent 3-week period. This treatment resulted in a mean weight loss of $3.80 \pm 1.64 \mathrm{~kg}$. Correlation analysis revealed that baseline concentrations of several hormones were significantly associated either with a higher (free triiodothyronine, C-peptide, growth hormone, pancreatic polypeptide) or with a lower (insulin-like growth factor-I, cortisol, adiponectin, neuropeptide $Y$ ) reduction of anthropometric parameters in response to weight management. In a backward stepwise regression model age, initial BMI together with baseline levels of growth hormone, peptide $Y Y$, neuropetide $Y$ and $C$ reactive protein predicted $49.8 \%$ of the variability in weight loss. Psychobehavioral factors (items of the Eating Inventory, Beck Depression score) did not contribute to weight change induced by a well-controlled short-term weight reduction program.
\end{abstract}

\section{Key words}

Obesity • Weight loss predictors • Hormones • Eating Inventory • Beck Depression Inventory - Anthropometric indexes

\section{Corresponding author}

Vojtěch Hainer, Institute of Endocrinology, Národní třída 8, 11694 Prague 1, Czech Republic. E-mail: vhainer@endo.cz

\section{Introduction}

Among the factors influencing weight loss and weight loss maintenance, hereditary, psychobehavioral, nutritional, metabolic and hormonal predictors play an important role. Twin and family studies revealed that weight loss is strongly controlled by genotype (Hainer et al. 2000a). Polymorphisms in obesity candidate genes affect the outcome of weight management (MorenoAliaga et al. 2005, Hainer et al. 2008). Energy and nutrient intake, as well as the level of physical activity, represent essential targets in weight management programs. It has been demonstrated that not only macronutrient intake but also intake of dietary calcium (Kabrnová-Hlavatá et al. 2007) and n-3 polyunsaturated fatty acids (Kunešová et al. 2006) might influence the outcome of weight management programs. Among the psychobehavioral factors level of depression, dietary disinhibition and their decrease in response to weight management significantly affect weight loss maintenance (Vogels et al. 2005). On the other hand, an increase in restraint score in response to weight management favorably influence weight loss maintenance. Metabolic predictors of weight loss and its maintenance include energy expenditure and substrate oxidation. Decreased energy expenditure and/or decreased ability to oxidize fat result in failure to maintain weight loss and in weight cycling (Ravussin 1995, Vogels et al. 2005, Hainer et al. 2000b). Special attention has been paid to hormonal predictors of weight loss and weight loss maintenance. A high baseline leptin/BMI ratio (Naslund et al. 2000), 
inadequately high decreases in leptin levels in response to weight management (Geldszus et al. 1996, Filozof et al. 2000, Celi et al. 2003) and lower ghrelin levels at baseline might predict failure in weight management. Lower baseline peptide YY levels and their weight management-induced increases have been shown to be associated with the highest levels of weight loss (Roth et al. 2005, le Roux et al. 2006). Substantial weight loss was shown to be associated with significantly lower obestatin and a tendency to higher ghrelin concentrations at baseline (Reinehr et al. 2007).

The aim of the current study was to evaluate the role of psychobehavioral and hormonal factors as predictors of weight loss in response to a 3-week weight management in-patient program conducted in a group of overweight and obese women.

\section{Methods}

Sixty seven women (Body Mass Index /BMI/: $32.4 \pm 4.4 \mathrm{~kg}$; age: $48.7 \pm 12.2 \mathrm{y})$ who exhibited stable weight on a $7 \mathrm{MJ} /$ day diet during the 1 st week of weight management obtained a hypocaloric diet providing $4.5 \mathrm{MJ} /$ day (protein $26.0 \%$, fat $28.0 \%$, carbohydrate $46 \%$ ) over the subsequent 3 -week period. Such a diet yielded an average daily energy deficit of $2.5 \mathrm{MJ}$ when compared with the pretreatment week. The comprehensive weight management included a welldefined, low calorie diet, which was supervised by a dietitian, daily physical activity supervised by a physiatrist and cognitive behavioral modification of the lifestyle. Energy and nutrient content of the meals prepared in the spa kitchen during the entire period of study were calculated using the PC program „Nutrition“ which covers about 3000 food items and evaluates the intakes of energy, macronutrients and micronutrients. All subjects were advised to eat each entire meal served in four daily portions in the spa eating room. Subjects with endocrine disorders or type 2 diabetes were excluded from the study. The participants did not take any medication susceptible to affect body weight.

The following psychobehavioral and hormonal parameters were examined before and after 3-week weight management: psychobehavioral parameters: Beck Depression Inventory (BDI - Beck et al. 1961), Eating Inventory (EI - Stunkard and Messick 1985); hormonal parameters: thyrotropin (TSH), free triiodothyronine (fT3), free thyroxine (fT4), insulin, C-peptide, prolactin (PRL), growth hormone (GH), insulin-like growth factor
I (IGF-I), cortisol, sex hormone binding globulin (SHBG), parathormone (PTH), ghrelin, leptin, peptide YY (PYY), neuropetide Y (NPY), pancreatic polypeptide $(\mathrm{PP})$, adiponectin, resistin and inflammatory parameter: C-reactive protein (CRP). Fasting levels of hormones were determined by radioimmunoassay, ELISA or electrochemiluminiscence using commercial kits. Total plasma ghrelin, leptin, adiponectin, PYY, PP and NPY were determined using RIA kits and resistin by ELISA of Linco Research, Inc. (St. Charles, Missouri, U.S.A.), prolactin, SHGB, GH and IGF-1 by RIA kits of Immunotech, Inc. (Prague, Czech Republic) and plasma insulin, C-peptide, fT3, fT4, PRL and CRP levels were measured on Modular Analytics E170 (Roche Diagnostics, GmbH, Mannheim). All assays were run twice in duplicate. After blood withdrawal, anthropometric measurements (body weight, height, waist and hip circumference) were carried out according to WHO recommendations (WHO Expert Committee, 1995). BMI and waist to hip ratio were calculated. Body composition was assessed by bioimpedance (BIA Tanita BC-418MA).

The study was performed in accordance with the Declaration of Helsinki and was approved by the Ethics Committee of the Institute of Endocrinology in Prague. Before the study, each participant signed an informed consent form.

\section{Statistical analysis}

Data were presented as means $\pm \mathrm{SD}$. We used Wilcoxon's robust paired test to compare the data before and after weight management. Pearson's correlations of weight management-induced changes in anthropometric indexes $(\Delta$ WEIGHT $(\mathrm{kg}), \Delta$ WEIGHT $(\%), \Delta$ BMI $\left(\mathrm{kg} / \mathrm{m}^{2}\right), \Delta$ WAIST $\left.(\mathrm{cm})\right)$ with age and baseline values of selected anthropometric, psychobehavioral and hormonal parameters were calculated. Subsequently, backward stepwise multiple regression analysis was performed to obtain the combined independent predictors of weight loss. Baseline values of anthropometric, psychobehavioral and hormonal parameters were used as independent variables. In regression analysis, Fisher's statistic $>4$ was used as inclusion criterium for individual parameters. Differences were considered significant at $\mathrm{p}<0.05$.

\section{Results}

The changes in anthropometric, psycho- 
Table 1. Anthropometric, psychobehavioral and hormonal characteristics before and after weight loss

\begin{tabular}{|c|c|c|c|c|c|c|c|}
\hline \multirow[b]{2}{*}{ Variable } & \multicolumn{2}{|c|}{ Before } & \multicolumn{2}{|c|}{ After } & \multicolumn{2}{|c|}{ Difference } & \multirow[b]{2}{*}{$p<$} \\
\hline & mean & SD & mean & SD & mean & SD & \\
\hline Weight (kg) & 84.6 & 12.9 & 80.8 & 12.6 & -3.8 & 1.6 & 0.000001 \\
\hline$B M I\left(\mathrm{~kg} / \mathrm{m}^{2}\right)$ & 32.40 & 4.51 & 30.90 & 4.36 & -1.50 & 0.63 & 0.000001 \\
\hline Waist (cm) & 98.8 & 12.0 & 93.6 & 11.5 & -5.2 & 2.3 & 0.000001 \\
\hline$H i p(\mathrm{~cm})$ & 115 & 9.3 & 112 & 9.1 & -3.4 & 1.6 & 0.000001 \\
\hline$W H R$ & 0.86 & 0.07 & 0.83 & 0.07 & -0.03 & 0.02 & 0.000001 \\
\hline Fat (kg) & 35.8 & 9.6 & 32.0 & 8.9 & -3.8 & 2.9 & 0.000001 \\
\hline Fat (\%) & 41.7 & 5.7 & 39.0 & 6.2 & -2.7 & 2.9 & 0.000001 \\
\hline$F F M(k g)$ & 48.8 & 4.7 & 48.5 & 5.4 & -0.3 & 3.2 & 0.035526 \\
\hline$T B W(\%)$ & 35.72 & 3.4 & 35.71 & 4.0 & -0.01 & 1.9 & NS \\
\hline$B D I$ - depression & 10.4 & 6.4 & 7.6 & 6.5 & -2.8 & 4.2 & 0.000003 \\
\hline EI - restraint & 10.0 & 4.6 & 12.9 & 4.6 & 2.9 & 4.3 & 0.000004 \\
\hline EI-hunger & 4.1 & 3.3 & 2.8 & 2.8 & -1.2 & 2.7 & 0.000641 \\
\hline EI - disinhibition & 6.6 & 3.0 & 4.9 & 2.7 & -1.7 & 2.6 & 0.000008 \\
\hline$C R P(m g / l)$ & 5.0 & 4.3 & 4.4 & 4.8 & -0.6 & 6.3 & 0.094821 \\
\hline TSH (mIU/l) & 4.0 & 12.2 & 4.3 & 12.2 & 0.3 & 3.2 & NS \\
\hline$f T_{4}(\mathrm{pmol} / \mathrm{l})$ & 15.9 & 4.9 & 16.3 & 4.9 & -0.4 & 3.1 & NS \\
\hline$f T_{3}(\mathrm{pmol} / \mathrm{l})$ & 4.96 & 1.93 & 5.04 & 1.67 & 0.08 & 0.84 & NS \\
\hline C peptide (nmol/l) & 0.92 & 0.35 & 0.93 & 0.31 & 0.01 & 0.04 & NS \\
\hline Glucose (mmol/l) & 5.1 & 1.6 & 4.8 & 1.3 & -0.3 & 1.7 & 0.045540 \\
\hline Insulin (mIU/l) & 8.37 & 4.49 & 7.83 & 4.85 & -0.50 & 6.04 & 0.048028 \\
\hline$I G F-I(\mu g / l)$ & 221.0 & 96.4 & 231.0 & 100.0 & 9.9 & 74.2 & 0.080448 \\
\hline Prolactin $(\mu g / l)$ & 20.0 & 16.4 & 25.3 & 23.6 & 5.3 & 21.1 & 0.009322 \\
\hline$G H(m I U / l)$ & 3.16 & 6.43 & 3.45 & 4.91 & 0.29 & 7.01 & NS \\
\hline Cortisol (nmol/l) & 924 & 531 & 888 & 273 & -41 & 462 & NS \\
\hline SHBG $(\mathrm{nmol} / \mathrm{l})$ & 61.5 & 44.6 & 79.1 & 54.1 & 14.9 & 26.9 & 0.000001 \\
\hline PTH (ng/l) & 40.7 & 18.0 & 43.4 & 17.3 & 2.7 & 25.9 & NS \\
\hline Adiponectin (mg/l) & 11.4 & 5.4 & 11.3 & 4.9 & -0.1 & 2.6 & NS \\
\hline Ghrelin (ng/l) & 1159 & 412 & 1169 & 423 & 10 & 213 & NS \\
\hline Leptin $(\mu g / l)$ & 21.2 & 9.1 & 15.4 & 7.2 & -5.9 & 6.5 & 0.000001 \\
\hline$P Y Y(n g / l)$ & 196 & 85 & 213 & 98 & 17 & 61 & NS \\
\hline NPY (nmol/l) & 102.0 & 52.7 & 84.0 & 41.4 & -18.0 & 31.7 & 0.000020 \\
\hline$P P(n g / l)$ & 47.1 & 38.4 & 44.3 & 40.0 & -2.8 & 22.4 & NS \\
\hline Resistin $(\mu g / l)$ & 2.4 & 0.8 & 2.2 & 0.8 & -0.2 & 0.8 & NS \\
\hline
\end{tabular}

$\mathrm{BMI}=$ body mass index, WHR = waist/hip ratio, FFM = fat free mass, TBW = total body water, BDI = Beck Depression Inventory, EI = Eating Inventory, CRP $=\mathrm{C}$ reactive protein, $\mathrm{TSH}=$ thyrotropin, $\mathrm{fT} 4=$ free thyroxine, $\mathrm{fT} 3=$ free triiodothyronine, $\mathrm{IGF}-\mathrm{I}=$ insulin growth factor I, GH = growth hormone, SHBG = sex hormone binding globulin, PTH = parathormone, PYY = peptide YY, NPY = neuropeptide $\mathrm{Y}, \mathrm{PP}=$ pancreatic polypeptide

behavioral and hormonal indexes are summarized in Table 1. Weight management resulted in significant decreases in all followed anthropometric and body composition parameters. Mean body weight decrease in response to 3 -week weight managment was $3.80 \pm 1.64$ $\mathrm{kg}$. Weight loss was accompanied by a significant increase in restraint score whereas Beck depression score, hunger score and disinhibition score exhibited a significant decrease. Among the hormones, insulin, leptin and NPY levels declined, while a significant rise was demonstrated in SHBG and PTH levels. No significant changes in the levels of the other determined hormones 
Table 2. Pearson's correlations of weight management-induced changes in anthropometric indexes ( $\Delta$ WEIGHT (kg), $\Delta$ WEIGHT (\%), $\Delta$ BMI $\left(\mathrm{kg} / \mathrm{m}^{2}\right), \Delta$. WAIST $\left.(\mathrm{cm})\right)$ with age and baseline values of selected anthropometric and hormonal parameters. Significant correlations are in bold.

\begin{tabular}{|c|c|c|c|c|}
\hline & $\Delta$ WEIGHT (kg) & $\Delta$ WEIGHT (\%) & $\Delta$ BMI $\left(\mathrm{kg} / \mathrm{m}^{2}\right)$ & $\Delta$ WAIST $(\mathrm{cm})$ \\
\hline \multicolumn{5}{|c|}{$A G E$ (years) } \\
\hline$r$ & -0.391 & -0.309 & -0.418 & -0.138 \\
\hline$p$ & 0.001 & 0.011 & 0.000 & 0.269 \\
\hline \multicolumn{5}{|c|}{ WEIGHT (kg) } \\
\hline$r$ & -0.255 & 0.079 & -0.192 & -0.151 \\
\hline$p$ & 0.039 & 0.529 & 0.122 & 0.225 \\
\hline \multicolumn{5}{|c|}{$B M I\left(k g / m^{2}\right)$} \\
\hline$r$ & -0.331 & -0.046 & -0.340 & -0.187 \\
\hline$p$ & 0.007 & 0.716 & 0.005 & 0.132 \\
\hline \multicolumn{5}{|c|}{ WAIST $(\mathrm{cm})$} \\
\hline$r$ & -0.268 & -0.005 & -0.253 & -0.138 \\
\hline$p$ & 0.030 & 0.969 & 0.041 & 0.268 \\
\hline \multicolumn{5}{|c|}{$f T_{3}(\mathrm{pmol} / \mathrm{l})$} \\
\hline$r$ & -0.308 & -0.276 & -0.304 & -0.325 \\
\hline$p$ & 0.012 & 0.025 & 0.013 & 0.008 \\
\hline \multicolumn{5}{|c|}{ C-PEPTIDE (nmol/l) } \\
\hline$r$ & -0.325 & -0.277 & -0.338 & -0.179 \\
\hline$p$ & 0.008 & 0.025 & 0.006 & 0.150 \\
\hline \multicolumn{5}{|c|}{$I G F-I(\mu g / l)$} \\
\hline$r$ & 0.313 & 0.244 & 0.344 & 0.131 \\
\hline$p$ & 0.011 & 0.050 & 0.005 & 0.300 \\
\hline \multicolumn{5}{|c|}{$G H(m I U / l)$} \\
\hline$r$ & -0.323 & -0.350 & -0.364 & -0.089 \\
\hline$p$ & 0.009 & 0.004 & 0.003 & 0.479 \\
\hline \multicolumn{5}{|c|}{ CORTISOL (nmol/l) } \\
\hline$r$ & 0.311 & 0.220 & 0.316 & 0.400 \\
\hline$p$ & 0.012 & 0.079 & 0.010 & 0.001 \\
\hline \multicolumn{5}{|c|}{ ADIPONECTIN $(\mathrm{mg} / \mathrm{l})$} \\
\hline$r$ & 0.042 & 0.006 & 0.069 & 0.308 \\
\hline$p$ & 0.738 & 0.962 & 0.582 & 0.012 \\
\hline \multicolumn{5}{|c|}{$\operatorname{LEPTIN}(\mu \mathrm{g} / \mathrm{l})$} \\
\hline$r$ & -0.229 & -0.067 & -0241 & -0.224 \\
\hline$p$ & 0.064 & 0.593 & 0.051 & 0.070 \\
\hline \multicolumn{5}{|c|}{$N P Y($ nmol/l) } \\
\hline$r$ & 0.212 & 0.256 & 0.225 & 0.192 \\
\hline$p$ & 0.087 & 0.038 & 0.070 & 0.122 \\
\hline \multicolumn{5}{|c|}{$P P(n g / l)$} \\
\hline$r$ & -0.258 & -0.207 & -0.255 & -0.254 \\
\hline$p$ & 0.036 & 0.096 & 0.039 & 0.040 \\
\hline \multicolumn{5}{|c|}{$C R P(m g / l)$} \\
\hline$r$ & -0.242 & -0.235 & -0.262 & -0.196 \\
\hline$p$ & 0.051 & 0.058 & $\mathbf{0 . 0 3 3}$ & 0.115 \\
\hline
\end{tabular}

$\mathrm{BMI}=$ body mass index, $\mathrm{fT} 3=$ free triiodothyronine, IGF I = insulin-like growth factor I, GH = growth hormone, NPY = neuropeptide $\mathrm{Y}$, $\mathrm{PP}=$ pancreatic polypeptide, $\mathrm{CRP}=\mathrm{C}$ reactive protein 
Table 3. Prediction of weight loss by age, BMI and baseline hormone levels as evaluated using the backward stepwise multiple regression (the final model)

\begin{tabular}{|c|c|c|c|c|}
\hline \multicolumn{5}{|c|}{ Dependent variable: $100 \times\left(\right.$ Weight $_{2}-$ Weight $\left._{1}\right) /$ Weight $_{1}$} \\
\hline \multirow{2}{*}{ Independent variables } & \multicolumn{2}{|c|}{ Parameter } & \multirow{2}{*}{ T-statistic } & \multirow{2}{*}{ P-Value } \\
\hline & Estimate & Standard Error & & \\
\hline Constant & 6.80 & 3.92 & 1.74 & 0.0881 \\
\hline Age $e^{1.75}$ & -0.00086 & 0.00039 & -2.16 & 0.0347 \\
\hline$-\left(B M I^{0.75}\right)$ & -48.56 & 23.07 & -2.11 & 0.0398 \\
\hline$-\left(G H_{l}^{-0.15}\right)$ & -2.75 & 0.875 & -3.15 & 0.0026 \\
\hline$-\left(P Y Y_{l}^{-0.35}\right)$ & 36.88 & 9.47 & 3.89 & 0.0003 \\
\hline$-\left(N P Y_{1}^{-0.14}\right)$ & 17.32 & 4.70 & 3.69 & 0.0005 \\
\hline $\log \left(C R P_{l}\right)$ & -0.556 & 0.197 & -2.82 & 0.0066 \\
\hline
\end{tabular}

$\mathrm{R}^{2}=49.8 \%$, Fisher's statistic $=9.26, \mathrm{p}<0.0001$, *Fisher's statistic $>4$ was used as inclusion criterium for individual parameters, BMI $=$ body mass index, $\mathrm{GH}=$ growth hormone, $\mathrm{PYY}=$ peptide $\mathrm{YY}, \mathrm{NPY}=$ neuropeptide $\mathrm{Y}, \mathrm{CRP}=\mathrm{C}$ reactive protein

were demonstrated.

Correlations between the changes in anthropometric variables $(\Delta$ WEIGHT $(\mathrm{kg}), \Delta$ WEIGHT (\%), $\Delta$ BMI $\left(\mathrm{kg} / \mathrm{m}^{2}\right), \Delta$ WAIST $\left.(\mathrm{cm})\right)$ and baseline values of those anthropometric, psychobehavioral and hormonal parameters which achieved statistical significance are shown in Table 2. Change in body weight (expressed both as $\mathrm{kg}$ and percentage) and BMI correlated negatively with age and with the fasting baseline levels of fT3, Cpeptide and $\mathrm{GH}$, and also correlated positively with the fasting baseline levels of IGF-I and cortisol. Baseline BMI and baseline waist circumference exhibited significant negative correlations with change in body weight $(\mathrm{kg})$ and BMI, whereas baseline body weight correlated with weight loss only if expressed in absolute values $(\mathrm{kg})$. The change in waist circumference was negatively related to baseline levels of fT3 and PP, whereas positive correlations were revealed between the change in waist circumference and baseline levels of cortisol and adiponectin. Baseline PP levels negatively correlated with changes in both body weight and BMI whereas baseline NPY levels positively correlated only with percent change in body weight.

Baseline CRP was inversely related to changes in BMI. However, its association with body weight change achieved only borderline significance. The relations of baseline leptin levels to changes in the anthropometric indexes were not significant although borderline significance was reached for changes in body weight $(\mathrm{kg})$, BMI and waist circumference. Baseline values of the Eating Inventory factors and Beck depression score did not correlate with the changes in the anthropometric measures.

Baseline values of parameters which appeared as significant predictors of weight loss in backward stepwise multiple regression are shown in Table 3 and Figure 1. Baseline levels of GH, PYY, NPY and CRP together with age and initial BMI predicted $49.8 \%$ of variability in weight loss after the 3 -week weight management.

\section{Discussion}

The magnitude of weight loss in response to a negative energy balance is determined by hereditary, psychobehavioral, nutritional, metabolic and hormonal factors. It has been shown in previous studies that longterm weight loss and weight loss maintenance is mainly influenced by psychobehavioral determinants, which affect lifestyle changes in eating behavior and physical activity. It is apparent that such a change in energy and nutrient intake and physical activity plays a crucial role in energy balance during weight management and thus the potential impact of hormonal determinants is obscured. In order to reveal potential hormonal determinants of weight loss in our study, a short-term weight reduction program was introduced in which both prescribed food intake and physical activity was under strict control during in-patient spa treatment. The prescribed diet yielded an average daily energy deficit of $2.5 \mathrm{MJ}$ in comparison with the pretreatment week. Negative energy balance over the 3 -week period resulted in a significant reduction of body weight $(-3.8 \pm 1.6 \mathrm{~kg})$ and waist circumference $(-5.2 \pm$ $2.3 \mathrm{~cm}$ ) accompanied by a significant improvement in all determined anthropometric and body composition 


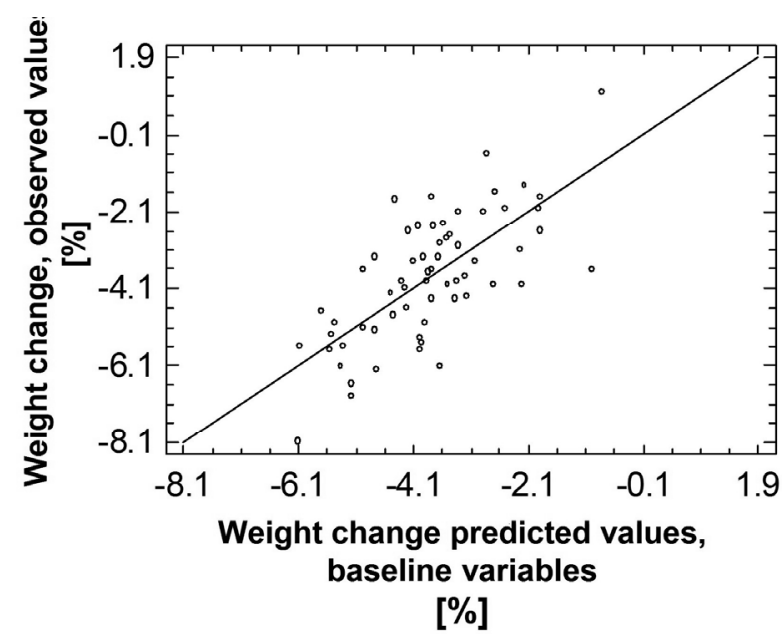

Fig. 1. Prediction of weight loss from age, BMI and baseline hormonal levels

indexes. Weight loss was mainly due to the loss of adipose tissue and cannot be attributed to the changes in body hydration as no changes in the content of total body water (TBW) were observed in response to the treatment. In agreement with previous studies the weight management program induced favorable changes in psychobehavioral characteristics (Wadden et al. 1987, Westerterp-Plantenga et al. 1998, Lejeune et al. 2003, Westenhoefer et al. 2004, Hainer et al. 2005, Vogels et al. 2005). A significant decrease in the Beck depression score, hunger and disinhibition scores along with a parallel significant increase in restraint score in response to short term weight management might contribute to a better outcome during the follow-up period.

In agreement with previous findings (Mingrone et al. 2002), significant decrease in serum insulin and a significant increase in serum SHBG concentrations were demonstrated as a consequence of weight loss. Low SHBG levels have been shown as a marker of insulin resistance and a strong independent risk factor for the development of type 2 diabetes in women (Lindstedt et al. 1991). Thus the weight management-induced increase in SHBG levels reflects improved insulin sensitivity, which resulted in a significant decline in the fasting blood glucose level. The hypothesis that increases in insulin sensitivity with weight loss are associated with subsequent weight regain were not confirmed in the study of Wing (1997).

We failed to show any significant changes in concentrations of plasma adiponectin, which has been noted as an important antiatherogenic, antidiabetic and an anti-inflammatory protein (Matsuzawa 2006). Discordant results have been published concerning the response of adiponectin to weight loss. After the weight loss either an increase (Behre et al. 2007) or no change (Xydakis et al. 2004) in adiponectin concentrations was demonstrated. These discrepancies might be due to the character of the treatment (duration of the treatment, magnitude of weight loss etc.). The observed significant decrease in leptin levels might be related to a reduction of body weight and fat stores (Pilcová et al. 2003) as well as to the weight management-induced negative energy balance which is associated with a decline in fasting insulin levels (Doucet et al. 2000). A significant decrease in the fasting level of NPY was demonstrated in response to weight loss. Previous studies failed to demonstrate any changes in plasma NPY levels in obese women after weight loss (Zahorska-Markiewicz et al. 2001, Nam et al. 2001, Moro et al. 1998) whereas a decrease in serum levels of NPY was observed in young obese men during the first phases of weight loss (Moro et al. 1998). Cerebrospinal fluid NPY levels were shown to decrease significantly in response to weight loss (Nam et al. 2001). This finding is in agreement with the experimental studies in obese rats who exhibited down regulation of hypothalamic NPY after weight loss induced by Roux-en-Y gastric bypass (Romanova et al. 2004). One could speculate that the decrease of orexigenic hormone NPY observed in our study might contribute to the simultaneous decline in hunger score after weight loss. However, no significant correlations of changes in the NPY level and hunger score were revealed.

Spontaneous prolactin release is considerably enhanced in obese women in proportion to the size of their visceral fat mass (Kok et al. 2004). We demonstrated a significant increase in prolactin level after weight loss. There have been contradictory results concerning the effect of weight loss on prolactin secretion. According to Kok et al. (2006) increased circadian prolactin secretion is blunted after weight loss in obese premenopausal women. On the other hand, short-term weight loss through a combination of dieting or dieting and exercise lead to higher plasma prolactin concentrations in lactating women (McCrory et al. 1999).

Hormones of the central nervous system, adipose tissue and gastrointestinal tract involved in the regulation of energy balance were investigated as predictors of weight loss. As shown in Table 2 the baseline values of several hormones influencing energy balance regulation were associated with a change in body weight (fT3, C-peptide, IGF1, GH, cortisol, PP and NPY), BMI (fT3, 
C-peptide, IGF1, GH, cortisol and PP) and waist circumference (fT3, cortisol, adiponectin and PP). Negative correlations with changes in anthropometric parameters were demonstrated for baseline values of fT3, C-peptide, GH and PP, whereas positive correlations were shown for those of IGF1, cortisol, adiponectin and NPY. In our study the baseline leptin levels exhibited borderline, but in contrast to other studies (Naslund et al. 2000, Verdich et al. 2001, Savoye et al. 2002, Sartorio et al. 2003), negative association with BMI change. Lower weight loss was reported in obese patients with a high leptin/BMI ratio (Naslund et al. 2000) and with high leptin levels adjusted for fat mass (Verdich et al. 2001, Sartorio et al. 2003). However, we failed to find a significant association between baseline leptin levels and change in anthropometric measures even after adjustment of leptin levels for BMI and fat mass. Di Stefano et al. (2000) described in children and adolescents a significant correlation between baseline leptin level and subsequent reduction in the BMI Z-score in response to a weight reduction program lasting 2 years. Discrepancies concerning the baseline leptin levels as predictors of weight loss might be due to the different protocols used in the studies. Our study evaluated a short-term weight loss, whereas that of Verdich et al. (2001) employed 24-week weight management regimen and others assessed weight changes over 2-year (Naslund et al. 2000) or 2.5-year (Savoye et al. 2002) follow-up. However, an inappropriately large decrease in leptin levels in response to weight management might predispose to subsequent weight regain (Geldszus et al. 1996, Filozof et al. 2000, Celi et al. 2003) and weight cycling (Benini et al. 2001). In a long-term weight reducing regimen a fall in leptin levels reflects a reduction in fat stores (Reinehr et al. 2005). Excessive limitation of energy intake leads to an exaggerated reduction of leptin levels which markedly exceeds that which corresponds to the reduction of fat stores (Miyawaki 2002). In this case leptin levels reflect energy deficit and not a reduction in fat stores. It is generally agreed that leptinemia is an important and sensitive indicator of energy balance, not just a pure marker of fat stores.

Baseline levels of fT3 were inversely related to changes in body weight (expressed as $\mathrm{kg}$ and \%), BMI and waist circumference. This means that higher levels of fT3 predicted greater reduction in the anthropometric indexes in response to weight management. No association between baseline concentrations of fT4 and changes in the anthropometric indexes was revealed. Our study supports the results obtained in euthyroid healthy Pima Indians after an average follow-up of 4 years which demonstrated that lower fT3, but not fT4 concentrations were independent predictors of sleeping metabolic rate, lipid oxidation and weight gain (Ortega et al. 2007). It is not surprising that fT3 as a predictor of sleeping metabolic rate and lipid oxidation predicted changes in body weight. We did not succeed in confirming the findings of Kozlowska and Rosolowska-Huszcz (2004), which reported that the ratio of both total and free thyroxine to TSH predicts weight loss.

Baseline levels of both $\mathrm{GH}$ and pancreatic polypeptide (PP) were inversely related to weight change. Secretions of both GH and PP are suppressed in obesity and reversed by weight loss (Scacchi et al. 1999, Reinehr et al. 2006). It is not surprising that the baseline GH level was associated with weight loss as GH increases lipid mobilization and energy expenditure. Low-dose recombinant human $\mathrm{GH}$ was successfully used as adjuvant therapy to lifestyle modifications in the management of obesity (Albert and Mooradian 2004). Although PP has been reported to reduce food intake in humans (Batterham et al. 2003, Jesudason et al. 2007), its clinical relevance in human obesity remains to be explained. On the other hand, baseline concentrations of orexogenic NPY were positively related to percent weight change (Table 2) and negatively to baseline levels of thermogenic fT3 $(r=-0.479, p=0.000)$ and anorexogenic PYY ( $r=-0.307, p=0.014)$. PYY is a hormone secreted postprandially in the distal intestine and binds to Y2 receptors of the NPY neurons in the arcuate nucleus of the hypothalamus, which leads to inhibition of food intake. We failed to find a significant correlation of the baseline PYY level with changes in anthropometric parameters. However, PYY significantly contributed to the prediction of weight loss in the backward stepwise regression model. Our finding is in agreement with that of Roth et al. (2005) who demonstrated that a low baseline PYY as well as its increase in response to oneyear weight management is related to successful weight loss in obese children. Postprandial increase in PPY level was shown to be associated with weight loss after bariatric surgery (le Roux et al. 2006).

Baseline insulin levels positively predicted weight loss in a six month weight loss trial carried out in overweight and obese women (Santosa et al. 2007). In our short-term study no significant associations of baseline insulin and C-peptide level with the changes in 
anthropometric parameters were demonstrated. Similarly, we failed to show a relationship between the baseline ghrelin concentrations and weight loss although children with substantial weight loss have recently been reported to have a tendency to higher ghrelin concentrations at baseline (Reinehr et al. 2007).

Baseline cortisol levels were positively related to changes in anthropometric parameters. These baseline cortisol concentrations were inversely related to initial values of BMI $(\mathrm{r}=-0.305, \mathrm{p}=0.013)$, waist circumference $(\mathrm{r}=-0.316, \mathrm{p}=0.010)$ and to concentrations of fT3 $(r=-0.463, p=0.000)$. This means that individuals with lower BMI and waist circumference have higher fasting cortisol concentrations and lower concentrations of the thermogenic fT3 and are more prone to lower weight reduction in response to a negative energy balance and vice versa. Our previously reported negative correlation between the fasting cortisol level and waist circumference in a cohort of obese non-diabetic females (Hainer et al. 2002) supports the findings of Rosmond et al. (1998) concerning the association of abdominal obesity with low morning cortisol values and suppressed diurnal cortisol variability. The results of our current study demonstrate that obese individuals with low morning cortisol concentrations, i.e. those with anticipated perturbations of the hypothalamic-pituitaryadrenal axis, are able to reduce weight more than those who do not exhibit such a disturbance.

Baseline adiponectin levels were positively related to changes in waist circumference, i.e. individuals with high baseline adiponectin levels exhibited a lower decrease in waist circumference than those with low baseline adiponectin levels. This relationship might be explained by the fact that there is an inverse association between adiponectin concentration and waist circumference at baseline $(r=-0.248, p=0.045)$ which reflects the role of adiponectin in the development of abdominal obesity and metabolic syndrome (Matsuzawa 2006). Subjects with higher adiponectin levels exhibited lower waist circumference at the beginning and thus have a lower chance for further decrease in this parameter.
We also investigated the predictive role of CRP, a biomarker of inflammation, which is associated with the risk of cardiovascular disease (Dietrich and Jialal 2005). Previous findings clearly demonstrated that increasing body weight is positively associated with CRP levels and weight loss significantly decreases CRP (Dietrich and Jialal 2005). Minor weight loss in our study did not lead to significant changes in CRP concentrations. However, an inverse relationship between the baseline CRP level and BMI change was shown in correlation analysis whereas log CRP contributed to the prediction of weight change in backward stepwise regression. This means that individuals with higher baseline BMI, and thus higher baseline CRP levels, are able to lose more weight in response to a weight reduction program.

\section{Conclusions}

The study indicated that a short-term weight management program induced many favorable changes in anthropometric, psychobehavioral and hormonal indexes. Correlation analysis revealed that the baseline concentrations of several hormones involved in energy balance regulation were significantly associated with the reduction of anthropometric parameters in response to a well-controlled weight reduction program. In the backward stepwise regression model age, initial BMI together with baseline levels of growth hormone, peptide $\mathrm{YY}$, neuropetide $\mathrm{Y}$ and $\mathrm{C}$-reactive protein predicted $49.8 \%$ of variability in weight loss. Psychobehavioral factors (items of the Eating Inventory, Beck Depression score) did not contribute to weight change in the weight reduction program with a well-controlled diet and exercise protocol.

\section{Conflict of Interest}

There is no conflict of interest.

\section{Acknowledgements}

This work was supported by a Grant Agency of the Czech Ministry of Health IGA NR/7800-4.

\section{References}

ALBERT SG, MOORADIAN AD: Low-dose recombinant human growth hormone as adjuvant therapy to lifestyle modifications in the management of obesity. J Clin Endocrinol Metab 89: 695-701, 2004.

BATTERHAM RL, LE ROUX CW, COHEN MA, PARK A, ELLIS SM, PATTERSON M, FROST GS, GHATEI MA, BLOOM SR: Pancreatic polypeptide reduces appetite and food intake in humans. J Clin Endocrinol Metab 88: 3989-3992, 2003. 
BECK AT, WARD CH, MENDESON M, MOCK J, ERBAUGH J. An inventory for measuring depression. Arch Gen Psychiat 4: 561-571, 1961.

BEHRE CJ, GUMMESSON A, JERNAS M, LYSTIG TC, FAGERBERG B, CARLSSON B, CARLSSON LM: Dissociation between adipose tissue expression and serum levels of adiponectin during and after dietinduced weight loss in obese subjects with and without the metabolic syndrome. Metabolism 56: 1022-1028, 2007.

BENINI ZL, CAMILLONI MA, SCORDATO C, LEZZI G, SAVIA G, ORIANI G, BERTOLI S, BALZOLA F, LIUZZI A, PETRONI ML: Contribution of weight cycling to serum leptin in human obesity. Int $J$ Obes 25: 721-726, 2001.

CELI F, BINI V, PAPI F, CONTESSA G, SANTILLI E, FALORNI A: Leptin serum levels are involved in the relapse after weight excess reduction in obese children and adolescents. Diabetes Nutr Metab 16: 306-311, 2003.

DIETRICH M, JIALAL I: The effect of weight loss on a stable biomarker of inflammation, C-reactive protein. Nutr Rev 63: 22-28, 2005.

DI STEFANO G, BINI V, PAPI F, CELI F, CONTESSA G, BERIOLI MG, BACOSI ML, FALORNI A: Leptin serum concentrations predict the responsiveness of obese children and adolescents to weight excess reduction program. Int J Obes 24: 1586-1591, 2000.

DOUCET E, ST-PIERRE S, ALMÉRAS N, MAURIÉGE P, DESPRÉS JP, RICHARD D, BOUCHARD C, TREMBLAY A; QUEBEC FAMILY STUDY: Fasting insulin levels influence plasma leptin levels independently from the contribution of adiposity: evidence from both a cross-sectional and an intervention study. J Clin Endocrinol Metab 85: 4231-4237, 2000.

FILOZOF CM, MURUA C, SANCHEZ MP, BRAILOVSKY C, PERMAN M, GONZALES CD, RAVUSSIN E: Low plasma leptin concentration and low rates of fat oxidation in weight-stable post-obese subjects. Obes Res $\mathbf{8}$ : 205-210, 2000.

GELDSZUS R, MAYR B, HORN R, GEISTHOVEL F, VON ZUR MUHLEN A, BRABANT G: Serum leptin and weight reduction in female obesity. Eur J Endocrinol 135: 659-662, 1996.

HAINER V, KUNEŠOVÁ M, PAŘÍZKOVÁ J, ŠTICH V, MIKULOVÁ R, SLABÁ S: Respiratory quotient in obesity: its association with an ability to retain weight loss and with parental obesity (In Czech). Sb Lek 101: 99-104, 2000a.

HAINER V, STUNKARD AJ, KUNEŠOVÁ M, PAŘÍZKOVÁ J, ŠTICH V, ALLISON D: Intrapair resemblance in very low calorie diet-induced weight loss in female obese identical twins. Int J Obes 24: 1051-1057, 2000b.

HAINER V, KUNEŠOVÁ M, PAŘÍZKOVÁ J, MIKULOVÁ R, STUNKARD A: Serum cortisol level and sex hormone binding globulin (SHBG) levels, body fat distribution and the role of genetic factors in obese females (In Czech). Sb Lek 103: 471-475, 2002.

HAINER V, KABRNOVÁ K, GOJOVÁ M, KUNEŠOVÁ M, KLEPETÁŘ J, DRBOHLAV J, KOPSKÝ V, NEDVÍDKOVÁ J, PAŘÍZKOVÁ J, HILL M: Psychobehavioral and hormonal predictors of weight loss in response to a 3-week weight management program. Obes Res 13 (Suppl): A142, 2005.

HAINER V, ZAMRAZILOVÁ H, SPÁLOVÁ J, HAINEROVÁ I, KUNEŠOVÁ M, ALDHOON B, BENDLOVÁ B: Role of hereditary factors in weight loss and its maintenance. Physiol Res 57(Suppl 1): S1-S15, 2008.

JESUDASON DR, MONTEIRO MP, MCGOWAN BM, NEARY NM, PARK AJ, PHILIPPOU E, SMALL CJ, FROST GS, GHATEI MA, BLOOM SR: Low-dose pancreatic polypeptide inhibits food intake in man. Br J Nutr 97: 426-429, 2007.

KABRNOVÁ-HLAVATÁ K, HAINER V, GOJOVÁ M, HLAVATÝ P, KOPSKÝ V, NEDVÍDKOVÁ J, KUNEŠOVÁ M, PAŘÍZKOVÁ J, WAGENKNECHT M, HILL M, DRBOHLAV J: Calcium intake and the outcome of short-term weight management. Physiol Res 2007 (In press).

KOK P, ROELFSEMA F, FROLICH M, MEINDERS AF, PIJL H: Prolactin release is enhanced in proportion to excess visceral fat in obese women. $J$ Clin Endocrinol Metab 89: 4445-4449, 2004.

KOK P, ROELFSEMA F, LANGENDONK JG, DE WITT CC, FROLICH M, BURGGRAAF J, MEINDERS AE, PIJL $\mathrm{H}$ : Increased circadian prolactin release is blunted after body weight loss in obese premenopausal women. Am J Physiol 290: E218-E224, 2006. 
KOZLOWSKA L, ROSOLOWSKA-HUSZCZ D: Leptin, thyrotropin, and thyroid hormones in obese/overweight women before and after two levels of energy deficit. Endocrine 24: 147-153, 2004.

KUNEŠOVÁ M, BRAUNEROVÁ R, HLAVATÝ P, TVRZICKÁ E, STAŇKOVÁ B, ŠKRHA J, HILGERTOVÁ J, HILL M, KOPECKÝ J, WAGENKNECHT M, HAINER V, MATOULEK M, PAŘÍZKOVÁ J, ŽÁK A, SVAČINA S: The influence of n-3 polyunsaturated fatty acids and very low calorie diet during a short-term weight reducing regimen on weight loss and serum fatty acids composition in severely obese women. Physiol Res 55: 63-72, 2006.

LEJEUNE MP, VAN AGGEL-LEIJSSEN DP, VAN BAAK MA, WESTERTERP-PLANTENGA MS: Effects of dietary restraint vs. exercise during weight maintenance in obese men. Eur J Clin Nutr 57: 1338-1344, 2003.

LE ROUX CW, AYLWIN SJ, BATTERHAM RL, BORG CM, COYLE F, PRASAD V, SHUREY S, GHATEI MA, PATEL AG, BLOOM SR: Gut hormone profiles following bariatric surgery favor an anorectic state, facilitate weight loss, and improve metabolic parameters. Ann Surg 243: 109-114, 2006.

LINDSTEDT G, LUNDBERG PA, LAPIDUS L, LUNDGREN H, BENGTSSON C, BJORNTORP P: Low sexhormone-binding globulin concentration as independent risk factor for development of NIDDM. 12-yr follow-up of population study of women in Gothenburg, Sweden. Diabetes 40: 123-128, 1991.

MATSUZAWA Y: The metabolic syndrome and adipocytokines. FEBS Lett 580: 2917-2921, 2006.

MCCRORY MA, NOMMSEN-RIVERS LA, MOLÉ PA, LONNERDAL B, DEWEY KG: Randomized trial of the short-term effects of dieting compared with dieting plus aerobic exercise on lactation performance. Am J Clin Nutr 69: 959-967, 1999.

MINGRONE G, GRECO AV, GIANCATERINI A, SCARFONE A, CASTAGNETO M, PUGEAT M: Sex hormonebinding globulin levels and cardiovascular risk factors in morbidly obese subjects before and after weight reduction induced by diet or malabsorptive surgery. Atherosclerosis 161: 455-462, 2002.

MIYAWAKI T, MASUZAKI H, OGAWA Y, HOSODA K, NISHIMURA H, AZUMA N, SUGAWARA A, MASUDA I, MURATA M, MATSUO T, HAYASHI T, INOUE G, YOSHIMASA Y, NAKAO K: Clinical implications of leptin and its potential humoral regulators in long-term low-calorie diet therapy for obese humans. Eur J Clin Nutr 56: 593-600, 2002.

MORENO-ALIAGA MJ, SANTOS JL, MARTI A, MARTÍNEZ JA: Does weight loss prognosis depend on genetic make-up? Obes Rev 6: 155-168, 2005.

MORO D, MAZZILLI G, GRUGNI G, GUZZALONI G, TEDESCHI S, MORABITO F: Leptin and neuropeptide Y serum levels in young obese during weight loss. Minerva Endocrinol 23: 105-110, 1998.

NAM SY, KRATZSCH J, KIM KW, KIM KR, LIM SK, MARCUS C: Cerebrospinal fluid and plasma concentrations of leptin, NPY, and alpha-MSH in obese women and their relationship to negative energy balance. $J$ Clin Endocrinol Metab 86: 4849-4853, 2001.

NASLUND E, ANDERSSON I, DEGERBLAD M, KOGNER P, KRAL JG, ROSSNER S, HELLSTROM PM: Associations of leptin, insulin resistance and thyroid function with long-term weight loss in dieting men. Intern Med 248: 299-308, 2000.

ORTEGA E, PANNACCIULLI N, BOGARDUS C, KRAKOFF J: Plasma concentrations of free triiodothyronine predict weight change in euthyroid persons. Am J Clin Nutr 85: 440-445, 2007.

PILCOVÁ R, ŠULCOVÁ J, HILL M, BLÁHA P, LISÁ L: Leptin levels in obese children: effects of gender, weight reduction and androgens. Physiol Res 52: 53-60, 2003.

RAVUSSIN E: Low resting metabolic rate as a risk factor for weight gain: role of the sympathetic nervous system. Int $J$ Obes 19 (Suppl 7): S8-S9, 1995.

REINEHR T, KRATZSCH J, KIESS W, ANDLER W: Circulating soluble leptin receptor, leptin, and insulin resistance before and after weight loss in obese children. Int J Obes 29: 1230-1235, 2005.

REINEHR T, ENRIORI PJ, HARZ K, COWLEY MA, ROTH CL: Pancreatic polypeptide in obese children before and after weight loss. Int J Obes 30: 1476-1481, 2006.

REINEHR T, DE SOUSA G, ROTH CL: Obestatin and ghrelin levels in obese children and adolescents before and after reduction of overweight. Clin Endocrinol (Oxf) 2007 (In press). 
ROMANOVA IV, RAMOS EJ, XU Y, QUINN R, CHEN C, GEORGE ZM, INUI A, DAS U, MEGUID MM: Neurobiologic changes in the hypothalamus associated with weight after gastric bypass. J Am Coll Surg 199: 887-895, 2004.

ROSMOND R, DALLMAN MF, BJORNTORP P: Stress-related cortisol secretion in men: Relationships with abdominal obesity and endocrine, metabolic and hemodynamic abnormalities. J Clin Endocrinol Metab 83: 1853-1859, 1998.

ROTH CL, ENRIORI PJ, HARZ K, WOELFLE J, COWLEY MA, REINEHR T: Peptide YY is a regulator of energy homeostasis in obese children before and after weight loss. J Clin Endocrinol Metab 90: 6386-6391, 2005.

SANTOSA S, DEMONTY I, LICHTENSTEIN AH, CIAFLONE K, JONES PJ: An investigation of hormone and lipid associations after weight loss in women. $J$ Am Coll Nutr 26: 250-258, 2007.

SARTORIO A, AGOSTI F, RESNIK M, LAFORTUNA CL: Effects of a 3-week integrated body weight reduction program on leptin levels and body composition in severe obese subjects. J Endocrinol Invest 26: 250-256, 2003.

SAVOYE M, DZIURA J, CASTLE J, DI PIETRO L, TAMBORLANE WV, CAPRIO S: Importance of plasma leptin in predicitng future weight gain in obese children: a two-and-a half-year longitudinal study. Int $J$ Obes 26: 942-946, 2002.

SCACCHI M, PINCELLI AL, CAVAGNINI F: Growth hormone in obesity. Int J Obes Relat Metab Disord 23: 260271, 1999.

STUNKARD AJ, MESSICK SM: The three-factor eating questionnaire to measure dietary restraint, disinhibition and hunger. J Psychosom Res 29: 71-83, 1985.

VERDICH C, TOUBRO S, BUEMANN B, HOLST JJ, BULOW J, SIMONSEN L, SONDERGAARD SB, CHRISTIANSEN NJ, ASTRUP A: Leptin levels are associated with fat oxidation and dietary-induced weight loss in obesity. Obes Res 9: 452-461, 2001.

VOGELS N, DIEPVENS K, WESTERTERP-PLANTENGA MS: Predictors of long-term weight maintenance. Obes Res 13: 2162-2168, 2005.

WADDEN TA, STUNKARD AJ, DAY SC, GOULD RA, RUBIN CJ: Less food, less hunger: reports of appetite and symptoms in a cotrolled study of a protein-sparing modified fast. Int J Obes 11: 239-249, 1987.

WESTENHOEFER J, VON FALCK B, STELLFELDT A, FINTELMANN S. Behavioural correlates of successful weight reduction over 3 y. Results from the Lean Habits Study. Int J Obes 28: 334-335, 2004.

WESTERTERP-PLANTENGA MS, KEMPEN KP, SARIS WHM: Determinants of weight maintenance in women after diet-induced weight reduction. Int J Obes 22: 1-6, 1998.

WHO EXPERT COMMITTEE Physical status: The use and interpretation of anthropometry. WHO Technical Series Report No. 854, Geneva, 1995, pp 452.

WING RR: Insulin sensitivity as a predictor of weight regain. Obes Res 5: 24-29, 1997.

XYDAKIS AM, CASE CC, JONES PH, HOOGEVEEN RC, LIU MY, SMITH EO, NELSON KW, BALLANTYNE $\mathrm{CM}$ : Adiponectin, inflammation, and the expression of the metabolic syndrome in obese individuals: the impact of rapid weight loss through caloric restriction. J Clin Endocrinol Metab 89: 2697-2703, 2004.

ZAHORSKA-MARKIEWICZ B, OBUCHOWICZ E, WALUGA M, TKACZ E, HERMAN ZS: Neuropeptide Y in obese women during treatment with adrenergic modulation drugs. Med Sci Monit 7: 403-408, 2001. 